\title{
TEACHING LARGE UNDERGRADUATE CHEMISTRY CLASSES: A CHALLENGE OR AN OPPORTUNITY?
}

\author{
Aishling Flaherty \\ National Centre for Excellence in Mathematics and Science Teaching and Learning, University of \\ Limerick, Ireland.
}

\section{Anne O'Dwyer}

National Centre for Excellence in Mathematics and Science Teaching and Learning, University of Limerick, Ireland.

\section{JJ Leahy}

Department of Chemical and Environmental Sciences, University of Limerick, Ireland.

\section{Oliver Richardson}

Department of Education and Professional Studies, University of Limerick, Ireland.

\begin{abstract}
Teaching introductory modules and classes of undergraduate programmes can present a number of subjective and objective challenges. Objective challenges include a high degree of variation in students' prior learning experiences combined with a high student-teacher ratio. Subjective challenges include the transitional changes which first year students undergo that include cognitive, affective and physiological changes as they make the leap from the often small and secluded secondarylevel environment to the all-consuming tertiary-level environment. For introductory chemistry modules, such as General Chemistry, the pertinence of these challenges can have negative repercussions on students' acquirement of basic chemical concepts in first year which could inherently go on to hinder their successful progression through their third-level education. In an effort to tackle the challenges posed against effective learning in General Chemistry modules, this exploratory research study set out to understand how the potential incorporation of a new approach to teaching and learning would be received by the three main cohorts involved. The attitudes and recommendations of undergraduate students, post-graduate students who have a role as laboratory demonstrators and module leaders towards the potential incorporation of Student-Inquiry activities and laboratories into General Chemistry were investigated. All three cohorts welcomed the incorporation of Student-Inquiry as part of the approach to teaching and learning. While the researchers and module leaders had an initial awareness of the challenges that come with teaching General Chemistry, little was known of the potential significance of the opportunity which lay amongst these challenges.
\end{abstract}




\section{Introduction}

\subsection{A Diverse Landscape}

International studies such as the Trends in International Mathematics and Science Study (TIMSS) and the Program for International Student Assessment, (PISA) can prove to be beneficial by informing curriculum change and reform. European countries have a good reputation for featuring amongst the top performing countries in these studies. As part of the 2011 TIMSS, three European countries featured in the Top 10 performing countries in the $4^{\text {th }}$ Grade, Science section of this study. In $3^{\text {rd }}$ place, Finland scored 570 , in $7^{\text {th }}$ place, the Czech Republic scored 534 and in $10^{\text {th }}$ place, Hungary scored 534 (Martin, Mullis, Foy, \& Stanco, 2012). The results from PISA 2012 indicate that four European countries featured in the Top 10 Mean Science Scores. With 501 being the average mean score for the science section of all participating countries, Finland scored 545, Poland scored 526 and Lichensteinn scored 525 (OECD, 2014).

The National Skills Strategy Research Report (NSSRR) sets out a number of objectives with the aim of enhancing Ireland's economy to be competitive, innovation-driven, knowledge-based and participative by 2020. One of the objectives proposed by this report describes how the progression rate to third level education will have to increase from $55 \%$ to 72\% (Forfás, 2007). In response to the demand for a highly educated and skilled workforce which this report calls for, there has since been an increase of $14 \%$ in the number of full-time undergraduate students enrolled in third level institutes across Ireland (Higher Education Authority, 2014).

The increasing infiltration of students into third level institutions in Ireland every year is resulting in the extensive diversification of the student landscape in terms of students' previous learning experiences, previous academic achievements and contrasting learning styles, particularly in the first year of undergraduate degree programs (Darmody \& Fleming, 2009). General Chemistry is one of the many first year subjects on offer that presents a plethora of contrasting student profiles which creates a challenge for General Chemistry educators. The contrasting characteristics of these student profiles include different experiences in learning chemistry, (Childs \& Sheehan, 2009; Lawrie et al., 2013; Regan, Childs, \& Hayes, 2011) different learning needs and different levels of cognitive skill (Francisco, Nicoll, \& Trautmann, 1998)

Third level institutions and first year, General Chemistry policy makers should identify the importance of prioritising the need to foster and cater for the learning needs of this diverse student landscape by employing an appropriate teaching and learning approach. Throughout the literature there have been several efforts to reform General Chemistry in regard to what is taught and how it is taught (Cooper, 2010; Havighurst, 1929; Lloyd \& Spencer, 1994; Sumter \& Owens, 2011; Taft, 1997). General Chemistry is critically important as it is responsible for providing students with a taster of major significant fields in chemistry such as analytical, organic and inorganic chemistry. This may prove to be a very important 
experience for students as on completion of General Chemistry, students may discover the field of chemistry which they are most passionate and have a real aptitude for.

\subsection{Potential of Inquiry?}

This research study investigated the potential incorporation of Student-Inquiry (SI) activities and laboratories into chemistry modules, with a particular emphasis on incorporating inquiry throughout General Chemistry laboratories. In the United States, the National Science Education Standards (National Research Council, 1996) describes SI in a learning environment as a multifaceted activity that sees students carry out the typical activities which a scientist would. These include "making observations; posing questions; reviewing literature; gathering, analysing and interpreting data; posing answers and explanations" (1996, pg. 23). In a General Chemistry laboratory setting, the inquiry-type laboratory would differ from the traditional laboratory in terms of student responsibilities. Weaver, Russell, and Wink (2008), explain that more decision-making powers and responsibility are issued to students during the procedure and analysis stages of inquiry-type General Chemistry laboratories, in contrast to students' main responsibilities during a traditional laboratory which is during data collection and interpretation stages.

Implementing inquiry-type laboratories into General Chemistry modules is a risk given that first year students may not have the background in either techniques or concepts of chemistry to complete the laboratories safely (Pavelich \& Abraham, 1979). However, it doesn't necessarily have to be a case of 'sink-or-swim' in a General Chemistry inquirylaboratory based on whether students have an extensive experience in learning chemistry or if they have no experience at all. $\mathrm{Xu}$ and Talanquer (2012), found that the level of inquiry which the laboratories are pitched at can be fine-tuned. The levels of inquiry used here progressed from initial verification experiments which required students to carry out few inquiry-type activities, to structured and guided laboratories which each required students to adopt a greater inquisitive mind-set respectively. It was found that student's written assignments for the inquiry-type General Chemistry laboratories they completed improved significantly in areas of knowledge, evaluation and future improvements (Xu \& Talanquer, 2012).

\subsection{Potential Barriers to Change}

A review of various attempts in changing instruction throughout undergraduate Science, Technology, Engineering and Mathematics (STEM) education conducted by (Henderson, Beach, \& Finkelstein, 2011) concluded that such attempts are not strong. The review outlines three ways in which change strategies can be made more effective in the hope of change being effectively realised. Firstly, those involved in the process of change must believe in the rationale provided for the attempt to implement change. Secondly, the change must be structured so that its implementation is designed to have long-term effects. Finally, having a deep understanding of the complexity of the third-level institute as a system is crucial to 
developing a change strategy that is complimentary and appropriate for the third-level system (2011). General Chemistry instruction was successfully initiated and sustained in the introductory chemistry course, Structure and Reactivity that was developed and led by Professor Seyhan Ege at the University of Michigan in the 1980's. The secret to enduring this reform of the General Chemistry curriculum is described as establishing a high degree of cooperation, a shared vision and trust amongst all the stakeholders involved such as faculty, administrators and students (Ege, Coppola, \& Lawton, 1997; Tobias, 1992).

\subsection{Acting Upon a Perceived Opportunity}

If a change to the currently employed approach to teaching and learning in General Chemistry is to be successfully sustained, such as Inquiry-Based Learning (IBL) and inquirytype laboratories, its success will depend on the instructional expertise of Graduate Teaching Assistants (GTA's) since this is the cohort responsible for instructing in laboratories (Luft, Kurdziel, Roehrig, \& Turner, 2004).Throughout literature, GTA's can be described in many different ways but for the purpose of this paper, the term 'Laboratory Demonstrator' (LD) will be used to describe a post-graduate research student who fulfils the role as a Demonstrator in an undergraduate teaching laboratory. LD's often begin laboratory instruction with very limited training and experience of becoming an instructor conducting inquiry-based experiments (Shannon, Twale, \& Moore, 1998). In order to develop the instructional expertise of LDs, appropriate training programs need to be established (DeChenne, Enochs, \& Needham, 2012; French \& Russell, 2002; Hammrich, 2001; Nurrenbern, Mickiewicz, \& Francisco, 1999). The potential benefits which could be realised by the development of LD's teaching skills are well documented. These benefits include

1. A positive effect on the academic achievement of both the students and the LDs (Ezrailson, 2004),

2. The development of a range of LD skills in terms of providing them with tools to pursue further faculty careers (Austin \& McDaniels, 2006),

3. The tools to increase their level of epistemological sophistication and metacognitive development (Sandi-Urena, Cooper, \& Gatlin, 2011),

4. The tools to enhance their career prospects (Partridge, Hunt, \& Goody, 2013),

5. The tools to improve their methodological research skills which are critical to their own research (Feldon et al., 2011; French \& Russell, 2002; McDonough, 2006)

The development of such skills may entice and attract LDs, however on review of a number of features in the changing landscape of STEM instruction, Seymour (2002) emphasises that the restructuring of a faculty rewards system is crucial to ensure and promote the quality of teaching and learning. LDs should be given some form accreditation along with informed insight into the potential benefits which they may accrue by completing a teacher training program.

This exploratory research study aims to address the following research questions: 
1. What are the attitudes and recommendations of Undergraduate Students, Laboratory Demonstrators and General Chemistry Module Leaders for the potential incorporation of Student-Inquiry activities in undergraduate chemistry laboratories?

2. What would be the outcome if the Post-Graduate Laboratory Demonstrators were provided with the tools to develop their teaching skills?

The project was carried out by a final year, science education student as part of a Final Year Undergraduate Research Project. The student is now using the findings of this project to inform further $\mathrm{PhD}$ research which is focused on the advancement of the teaching and learning approaches employed throughout General Chemistry.

\section{Methodology}

This research project was carried out in three consecutive phases. Phases 1, involved Undergraduate Students, Phase 2 involved Post-Graduate Laboratory Demonstrators (LDs) and Phase 3 involved General Chemistry Module Leaders.

\subsection{Phase 1}

Phase 1 involved 15 Undergraduate Students from a $2^{\text {nd }}$ year analytical chemistry module, participating in a classroom-based tutorial that required students to prepare, conduct and evaluate a hypothetical Student-Inquiry (SI) laboratory experiment. The experiment was based on the application of Infrared (IR) Spectroscopy whereby students were required to solve a scenario. The scenario was developed by the researchers and an analytical chemistry expert. This tutorial was implemented at the end of the autumn semester so that students could apply the chemical knowledge which they gained throughout their experiences of $1^{\text {st }}$ year General Chemistry and $2^{\text {nd }}$ year Analytical Chemistry.

The students were divided into three groups to solve the scenario. Following on from their completion of the tutorial, students were informed of the Inquiry-Based teaching approach that was implemented. Students then completed a questionnaire which was designed to probe for their attitudes of their experiences of the hypothetical SI laboratory. The questionnaire that was compiled and distributed for this study was modelled on the questionnaire that was designed by (Chatterjee, Williamson, McCann, \& Peck, 2009) for their study which investigated students' attitudes towards Guided-Inquiry and Open-Inquiry Laboratories. Permission to use and model our questionnaire on the model Chatterjee et al. (2009) designed was granted prior to the implementation of this study.

The questionnaire was divided into three parts. Part A sought to understand their attitudes to the traditional, currently employed Teacher-Led (TL) Laboratory whilst the second part, Part B sought to understand their attitudes to the hypothetical SI Laboratory proposed during the tutorial. Both parts were made up of a number of statements (Table 1) whereby students rated their agreement to each. A 5-point Likert scale was employed for each student to rate their agreement to each statement whereby ( $1=$ Strongly Agree, $5=$ Strongly Disagree). Each of the five points was allocated a number from 1 to 5 for the purpose of 
numerical analysis using SPSS (Software Package for Social Sciences, v.21). Participants responses to the statements were reported in mean ratings. Their attitudes towards each type of laboratory was then compared and contrasted.

The third part, Part C of the questionnaire consisted of an open-ended question to identify students' recommendations towards the potential incorporation of SI activities and laboratories in chemistry modules:

1. "What do you recommend Module Leaders should keep in mind when implementing Student-Inquiry activities - What would cause students difficulty?"

Students' responses were coded and themed through the collaboration and consultation of the researchers involved in this research project.

\subsection{Phase 2}

Phase 2 involved 17 LDs who were provided with an information sheet describing the processes involved in SI activities and laboratories. The LDs were then required to complete a questionnaire that consisted of two parts. The first part of the questionnaire, Part A was designed to probe for their attitudes and perceptions of their role as LDs in the laboratory and their attitudes to SI activities and laboratories. A five-point Likert scale was used for each statement in Table 3.2 ( $1=$ Strongly Agree, $5=$ Strongly Disagree).

The second part of the questionnaire, Part B consisted of the following open-ended question:

1. What would you recommend and suggest Module Leaders bear in mind when planning on implementing Student-Inquiry (SI) activities and laboratories into chemistry modules?

The LDs responses were coded and themed through the collaboration and consultation of the researchers involved in this research project. Background information on each LD such as their post-graduate research interests, their previous experience of the teaching and laboratory demonstrating and whether they had previously received teacher training or teacher skill development was also gathered.

\subsection{Phase 3}

Phase 3 involved three General Chemistry Module Leaders participating in semi-structured interviews probing for their opinions of incorporating SI activities into General Chemistry modules. All interviews were recorded using a dictaphone to preserve anonymity and for the purpose of transcription after the interviews had taken place. The Module Leaders' responses were then analysed, coded and themed through the collaboration and consultation of the researchers involved in this research project. 


\section{Results}

\subsection{Undergraduate Students' Attitudes and Recommendations}

\subsubsection{Undergraduate Students' Attitudes}

Undergraduate Students' attitudes to both the traditional, currently employed Teacher-Led (TL) Laboratory and the hypothetical Student-Inquiry (SI) laboratory were identified by reporting the mean rating of students' agreement to a number of statements on each type of laboratory ( $1=$ Strongly Agree, $5=$ Strongly Disagree). It was decided to report in terms of mean ratings given that this is the way Chatterjee et al. (2009) reported their finding from their questionnaire which was used as a model for the development of the questionnaire for this study. A Paired T-Test was then carried out to compare the students' mean ratings of both types of laboratories. Table 1 represents the mean distribution of student agreement for each aspect of both types of laboratories. The standard deviations and median ratings are also reported.

There was a significant difference in the students' attitudes towards both types of laboratories for five out of the nine statements. These five aspects included, the amount of interest generated $(p=0.044)$, the amount of fun experienced $(p=0.045)$, the extent of correlation between theory and experimental method required to complete the experiment ( $p=0.043)$, the degree of deep thinking required $(\mathrm{p}=0.025)$ and, the effort associated with the completion of each laboratory session $(\mathrm{p}=0.026)$. From analysis of these results, Students indicated that SI Laboratories are more interesting and fun even though they felt that this type of laboratory would require them to think more and to correlate their experimental outcomes to background theory more than TL laboratories. 
Table 1 Mean distribution of undergraduate students' agreement for each aspect of both types of laboratories where $1=$ Strongly Agree, $5=$ Strongly Disagree $(n=15)$.

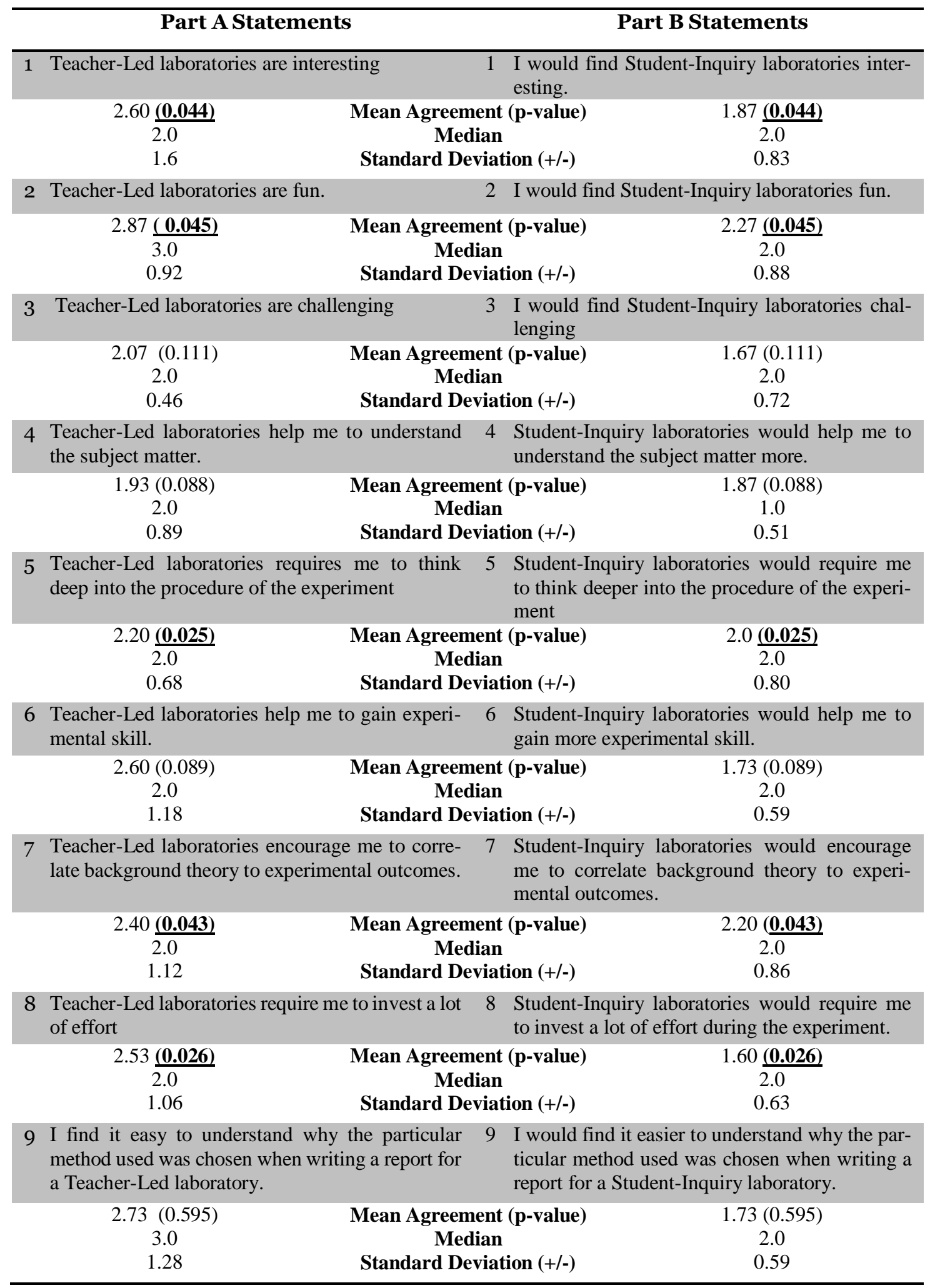




\subsubsection{Undergraduate Students' Recommendations}

Undergraduate students' recommendations to module leaders for the potential incorporation of SI activities into chemistry laboratories were identified and evaluated through their responses to the following open-ended question.

Question 1: What do you recommend module leaders should keep in mind when implementing Student-Inquiry activities? What would cause students difficulty?

Introvert Personalities. 11 (33\%) of students identified that personal characteristics such as introverted personalities, shyness or fear of contributing opinions or ideas during groupwork activities would cause students difficulty. "Fear of asking questions. For this to work well, students must feel comfortable in asking their peers and teachers questions" (Questionnaire.No.4). Another student highlighted that students' self-belief is of importance: "If they were paired with other students of higher ability which may cause them to feel lost and become disengaged" (Questionnaire.No.12).

Differences in students' prior knowledge and experience of chemistry. 17 (28\%) of students indicated that a lack of understanding of the subject content would cause students difficulty during the Inquiry process. Students expressed concern in participating in SI activities with others who would have completed chemistry before during second-level education or who would have already had acquired a greater and more robust understanding of chemistry during the semester. They perceived that their lack of chemical understanding and experience would hinder their successful engagement in the SI activity and thus, render their learning experiences to be less beneficial. One student stated that "Module leaders should understand that students have different levels of chemistry and that some students would find this approach challenging. If a lecturer explained the theory and what you were looking for in the experiment and you then carried it out on your own, it would be beneficial" (Questionnaire.No.2).

Weak problem-solving abilities. Students also acknowledged that the nature of the particular SI scenario used, which lends itself to having students solve eight problems, required a set of cognitive skills which they thought could differ considerably between students. Both the students who struggled to solve the problems as well as the students who found the problems easier to solve felt that differences in students' problem-solving abilities could prove to be a very significant and contributing factor to their engagement in the SI activity.

\subsection{Laboratory Demonstrators' Attitudes and Recommendations}

\subsubsection{Laboratory Demonstrators' Attitudes}

LDs attitudes were reported, in the same way as students' attitudes in terms of their mean agreement with a number of statements. These statements, along with the LDs mean rating of agreement can be found in Table 3.2. LDs were in strongest agreement with the statement "The implementation of Student-Inquiry activities in science laboratories would be effective for promoting positive learning experiences for students" (mean rating = 1.5, Table 2). 
LDs expressed confidence and belief in the current approach to teaching and learning in chemistry laboratories. This was shown through their strongest disagreement with the statement "There is a need for the current teaching strategy that is used in today's chemistry laboratories to be reviewed and changed" (2.941). They showed particular faith in the efficacy of laboratory teaching tools such as the pre-laboratory lecture (1.765) and the laboratory manual (1.588). Despite expressing concern over the lack of opportunities available to them to develop their teaching skills, with a view to improving students' learning experiences, it was clear that LD's did not perceive their role, as educators in the laboratory as part of the approach to teaching and learning implemented. Demonstrators' agreed that their role in the laboratory should be based on their active engagement with each group of students by asking them questions (1.765) and asking them to make predictions about the experimental outcome (1.765).

Table 2 Laboratory Demonstrators' Mean Rating of Agreement to the Statements where $1=$ Strongly Agree and $5=$ Strongly Disagree. $(n=17)$

\begin{tabular}{|c|c|c|c|c|}
\hline & Statement & $\begin{array}{l}\text { Mean } \\
\text { Rating }\end{array}$ & Median & $\begin{array}{l}\text { Standard } \\
\text { Deviation } \\
\quad(+/-)\end{array}$ \\
\hline 1 & $\begin{array}{l}\text { A pre-laboratory introductory lecture which describes the } \\
\text { procedure of the experiment is a good way to prepare students } \\
\text { for an effective learning experience. }\end{array}$ & 1.77 & 1.0 & 1.03 \\
\hline 2 & $\begin{array}{l}\text { A laboratory demonstrator should provide all the necessary } \\
\text { information to a student who is having difficulty with a task in } \\
\text { an experiment. }\end{array}$ & 2.47 & 2.0 & 1.01 \\
\hline 3 & $\begin{array}{l}\text { A laboratory demonstrator should fix any mistakes students } \\
\text { make during experimentation. }\end{array}$ & 2.82 & 3.0 & 1.13 \\
\hline 4 & $\begin{array}{l}\text { A laboratory demonstrator should actively engage with each } \\
\text { group of students during an experiment by asking them } \\
\text { questions about the method they are following. }\end{array}$ & 1.77 & 2.0 & 0.56 \\
\hline 5 & $\begin{array}{l}\text { A laboratory demonstrator should actively engage with each } \\
\text { group of students during an experiment by asking them to } \\
\text { make predictions about the experimental outcome. }\end{array}$ & 1.77 & 2.0 & 0.66 \\
\hline 6 & $\begin{array}{l}\text { The role of a laboratory demonstrator is beneficial to the } \\
\text { development of one's own research skills. }\end{array}$ & 2.18 & 2.0 & 1.18 \\
\hline 7 & $\begin{array}{l}\text { The role of a laboratory demonstrator allows for deeper insight } \\
\text { into the scientific method. }\end{array}$ & 2.24 & 2.0 & 1.03 \\
\hline 8 & $\begin{array}{l}\text { The laboratory manual is a good tool for students to learn how } \\
\text { to carry out experiments. }\end{array}$ & 1.59 & 2.0 & 0.51 \\
\hline 9 & $\begin{array}{l}\text { There is a need for the current teaching strategy that is used in } \\
\text { today's chemistry laboratories to be reviewed and changed. }\end{array}$ & 2.94 & 2.0 & 1.21 \\
\hline 10 & $\begin{array}{l}\text { The implementation of Student-Inquiry (SI) activities in } \\
\text { science laboratories would be effective for promoting positive } \\
\text { learning experiences for students. }\end{array}$ & 1.50 & 1.0 & 0.63 \\
\hline 11 & $\begin{array}{l}\text { Laboratory demonstrators are provided with opportunities to } \\
\text { develop their laboratory teaching skills for effective student } \\
\text { learning experiences. }\end{array}$ & 2.87 & 2.5 & 1.45 \\
\hline
\end{tabular}




\subsubsection{Laboratory Demonstrators' Recommendations}

LDs recommendations to Module Leaders for the potential incorporation of SI activities were identified and evaluated through their responses to the following questions in Part $\mathrm{C}$ of the student questionnaire.

What would you recommend Module Leaders bear in mind when planning on implementing Student-Inquiry (SI) activities and laboratories into chemistry modules?

The responses of the LDs to this question were coded and categorised into three themes which focused on the selection and preparation of participants and the design of the SI activity:

The Selection and Preparation of the Student. 53\% (9) of the LDs suggested that Module Leaders take into account the selection and preparation of students. It was often noted that students with a greater aptitude and motivation for chemistry would reap more learning benefits from SI activities and laboratories. One LD gave a suggestion of how students could be prepared for the process of inquiry "To suggest a literature review to the students and they have to answer some questions before coming to the lab" (Questionnaire O).

The Selection and Preparation of the Laboratory Demonstrator. 18\% (3) of the LDs believe that the selection and preparation of the Laboratory Demonstrators is an area which should also be given attention. "Prepare lab demonstrators, especially if the module is new to them" (Questionnaire M) and "Better training for demonstrators and more resources in the lab" (Questionnaire D). From the background data collected on each LD at the beginning of the questionnaire, it was found that 82\% (14) of the LDs had no prior experience of teaching. Only two LD's indicated that they had previous experience of general teacher training and from their undergraduate studies of science with concurrent teacher education.

The Design of the Student-Inquiry Activity. According to $29 \%$ (5) of the LDs, an important area to consider is the design of the SI laboratory. LD's commented, "It is important to design the labs carefully to remove the students' attitudes of gathering the data and learning to write it up. Place more emphasis on discussing what happened rather than the results obtained" (Questionnaire K) and "Organise it well” (Questionnaire J).

\subsection{Module Leaders' Recommendations}

The Module Leaders' recommendations for the incorporation of SI activities and laboratories into General Chemistry were analysed and coded into five themes which relate to timing, resources, structure, participant selection and integration of technology.

Appropriate Timeline. The Module Leaders emphasised that the timing of any change to the currently employed approach to teaching and learning would be crucial to its impending success. It was suggested to introduce change slowly and incrementally rather than a sudden and dramatic pedagogical overhaul. 
Appropriate and Readily Available Resources. Funding and personnel were singled out as being two very significant resources that would be needed in abundance for a change to be established and sustained.

Appropriate Structuring of the Inquiry in the SI activity. If a change is to be considered for effective implementation, the need for it to be organised and structured was stressed. Module Leaders appreciated that implementing SI activities could become difficult if the depth of inquiry which the activity is pitched at is not suitable for students or other module stakeholders to take on.

Appropriate Selection of Participants. The correct selection of students and LDs was something which the Module Leaders felt strongly about. They thought that the cohort of students with prior experiences of chemistry may benefit more from SI activities because it is perceived they will more likely be more motivated to develop a deeper understanding of chemistry. The LDs teaching and demonstrating experience is also an important aspect that should be considered when selecting LDs. They acknowledged that LDs with a greater experience of demonstrating or with a background in teaching or science education may be more open to embracing change.

Technology to Stimulate Creativity and Innovation. Module Leaders recommended that it is important to embrace the technological revolution that the world is currently experiencing by incorporating aspects of technology to help students become more creative and innovative during times of inquisition. The Module Leaders paid acknowledged the ever advancing field of classroom and laboratory based technological pedagogy and gave examples of tools which could be incorporated or considered such as videoing tools, visual representations and the use of audio technology.

\section{Discussion}

\subsection{Research Question 1: Attitudes and Recommendations}

Participants in this project were all unanimous in their agreement and recommendation for the incorporation of SI activities and laboratories in both undergraduate chemistry modules and General Chemistry.

Undergraduate Students' Attitudes and Recommendations. Undergraduate students indicated that SI Laboratories are more interesting and fun even though they felt that this type of laboratory would require them to think more and to correlate their experimental outcomes to background theory more than TL laboratories.

The diagnostic instrument which was designed for the purpose of understanding students' attitudes towards SI laboratories was developed and modelled on the instrument which was developed by Chatterjee and her team (2009). The findings of this research study support the findings of Chatterjee et al. (2009). Students' from both studies found that SI laboratories require more "deep thinking" and both cohorts believed that they would gain a 
better understanding of the subject matter of the experiment on completion of the SI laboratory report.

A correlation was found between the attitudes of the students in this research study and the attitudes of students towards SI laboratories found by Deters (2005). Deters found that students feel SI laboratories require more effort which corresponds to the attitudes held by students in this research project, "Student-Inquiry laboratories would require me to invest a lot of effort during the experiment" (mean rating $=1.60$ ). "Increased interest" and "learning chemistry concepts" were also two positive aspects which Deters (2005) found students had towards SI laboratories. Students in this study had a mean rating agreement of 1.87 with the statement "I would find Student-Inquiry laboratories interesting" and a mean rating of 1.97 with the statement "I would find it easier to understand why the particular method used was chosen when writing a report for a Student-Inquiry laboratory."

Students recommended that when implementing SI activities, Module Leaders must bear in mind that while some students will have personality traits which they consider to be conducive to participating and engaging in collaborative, inquiry-based groupwork tasks, others may be a little more introverted and reserved which will cause them to refrain from fully engaging. Students also felt that their previous chemical experience and cognitive ability, such as problem-solving skills are two factors which will also determine the extent of their participation.

Post-Graduate Laboratory Demonstrators (LD's) Attitudes and Recommendations. LDs were in strong support for the incorporation of SI laboratories with a view to promoting effective student learning. This was shown through the statement which they had strongest agreement with: "The implementation of Student-Inquiry activities in science laboratories would be effective for promoting positive learning experiences for students" (mean rating $=1.5$ ). When implementing such SI activities, LDs recommended that module leaders must carefully consider the participants and the structure of the design of the SI activity. Motivation was the only trait which demonstrators particularly emphasised. They felt that the students and demonstrators who participate in the SI laboratory must be motivated to engage in the activity in order for them to fully benefit. Crouch and Mazur (2001)provides evidence from a 10-year Harvard University study which investigated the effect of Peer Instruction in the physics classroom concluded that those who are more motivated to achieve will benefit more from a new approach to teaching and learning, such as Peer Instruction and SI activities and laboratories.

Module Leaders Recommendations. All three Module Leaders expressed their support for the incorporation of SI activities and laboratories in chemistry modules. Their recommendations for such incorporation were generalised into five over-arching themes which include: Timing, Resources, Structure, Participant selection and Preparation and the Integration of technology.

Cacciatore and Sevian (2009), emphasises that the incorporation of IBL in General Chemistry must be carried out in an incremental basis. The Module Leaders suggested that 
if such an incorporation or change to the teaching and learning approach that is currently adopted in laboratories is made too quickly, it could prove to be detrimental to its successful establishment. Hofstein and Lunetta (2004), identified that many laboratories remain traditional in pedagogy given the barriers which prevent wholesale change to the teaching and learning strategy, notable cost and institutional capacities. Module Leaders felt the need for the inclusion of novel and innovative technology in the SI approach was important. The findings from Lee, Linn, Varma, and Liu (2010) revealed that technology-enhanced inquiry instruction was much more effective than typical instruction.

\subsection{Research Question 2: Acting on Opportunity}

Pedagogically-Informed Laboratory Demonstrators. As this exploratory research progressed, the challenges that can be associated with teaching large General Chemistry courses and challenges associated with modifying the existing approach to teaching and learning in this module, such as the incorporation of SI activities were identified. However, in an effort to relieve the repercussions which these challenges present, the progression of this project led researchers to identify and perceive a very potent opportunity.

If the SI approach is to be adopted into large General Chemistry modules, a change to the currently employed approach to teaching and learning will have to be made. The Henderson et al. (2011) meta-study concluded that recent efforts to change STEM instruction are not strong. However, an example of a successful change is the change made to the teaching and learning approach by Professor Seyhan Ege to General Chemistry at the University of Michigan in the 1980's. The key to the success of this change was regarded in the establishment of a high degree of cooperation, a shared vision and trust amongst all the stakeholders involved such as faculty, administrators and students (Ege et al., 1997; Tobias, 1992).

This research project gained insight into the importance of the LDs in General Chemistry laboratories. The importance of their role allocates them with just as much stake in the module as other, more obvious module stakeholders and participants such as the students and lecturers. Nurrenbern et al. (1999) states that "They (LDs) play a major role in bringing about the desired department and faculty goals in introductory chemistry courses where class sizes of 40o-6oo students are not unusual" (1999 p. 114). If the SI approach is to be implemented successfully, Luft et al. (2004) informs that its success will depend on the instructional expertise of the LDs. Luft et al. (2004), went on to show that the instructional skill of GTA's is not appropriate to teach Inquiry-Based activities and laboratories effectively. This project found that

- $82 \%$ (13) of the LDs have no prior experience of Inquiry-Based teaching or learning techniques and

- No LD had previously participated in a program or workshop with the intention of developing their teaching skills. 
The LDs in this project called for more opportunities to develop their teaching skills though their disagreement with the statement "Laboratory demonstrators are provided with opportunities to develop their laboratory teaching skills for effective student learning experiences." (Mean rating $=2.87$ ). However, they didn't believe that the current approach to teaching and learning in the laboratory is in need of review and change. LDs disagreed with the statement "Laboratory demonstrators are provided with opportunities to develop their laboratory teaching skills for effective student learning experiences." (Mean rating = 2.94). It was made clear here that the LDs did not perceive their role as been an essential element of the teaching approach employed in laboratories.

There is opportunity to develop the teaching skills of the LDs and to make them aware of the importance of their role in a laboratory teaching. The benefits that could arise for both the LDs and the students from acting on this opportunity to develop the teaching and pedagogical skills of the LD's are very well documented. (Austin \& McDaniels, 2006; Ezrailson, 2004; Feldon et al., 2011; French \& Russell, 2002; McDonough, 2006; Partridge et al., 2013; Sandi-Urena et al., 2011). By training LDs as teachers, the most prevalent challenges associated with teaching large General Chemistry modules may begin to be resolved. For example, the student-teacher ratio could be significantly reduced, from 1:700 in a lecture theatre environment to 1:15 in a laboratory setting of 60 students and 4 LDs. In order for the development of LDs teaching skills, an appropriate and accredited training program needs to developed, in an effort to improve the learning outcomes of students enrolled in large, first year General Chemistry Modules.

Some directions for the $\mathrm{PhD}$ research project of one of the principal researchers involved in this study, which has stemmed from the findings of this Final Year Undergraduate Project include

- The development, implementation and analysis of a training module for PostGraduate Laboratory Demonstrators with the aim of developing their teaching skills

- The development, implementation and analysis of different pedagogical tools and interventions that can be employed throughout General Chemistry modules for the enhancement of undergraduate students' learning experiences.

\subsection{Limitations of Research Study}

While this research study accounts for the recommendations and suggestions of the main cohorts involved in the delivery of a General Chemistry module towards the incorporation of SI activities and laboratories, the generalisation of the findings of this study must be considered. The main generalisation made during the analysis of the findings occurred as a result of the voluntary nature of the participation of students and LD's. Indeed, while the sample size of students $(\mathrm{N}=15)$ and LD's $(\mathrm{N}=17)$ is low, their respective contributions in the form of their recommendations and suggestions are similar. The students who attended the SI tutorial on a voluntary basis also exhibited notable determination and motivation in pursuit of improving their understanding of chemistry. Therefore, this cohort may be more 
inclined to accept and support the incorporation of alternative approaches to learning in undergraduate modules.

Finally, the incorporation of an SI approach to learning was recommended, however the authors are mindful that a larger cohort of students will require appropriate and sufficient time, guidance and motivation to be inducted into an inquiry-based learning mind-set.

\section{Conclusion}

This study found that students, LDs and module leaders were all unanimous in their support for the inclusion of SI activities into the teaching and learning approach adopted in General Chemistry. The recommendations of students and LDs were subjective in nature by focusing on the appropriate selection and preparation of participants for the SI activities. However, the recommendations of module leaders were inclined to be more objective in nature by focusing on the practicalities of facilitating the incorporation of SI activities in General Chemistry such as time, resources and the appropriate structuring.

The findings of this exploratory research provide a valuable insight into the challenges associated with teaching large chemistry classes at third level. It also provides evidence for the need to act upon the opportunity to develop the teaching skills of laboratory demonstrators. Although this research was carried out in Ireland, these findings can provide useful perspective for other chemistry education researchers.

Teaching General Chemistry modules can be complex given the number of subjective and objective challenges which the diverse nature of a cohort of 600-700 first year students presents. In order to address this and to begin to resolve some of these challenges, this project found that undergraduate students, LD's and module leaders would all welcome the incorporation of SI in General Chemistry modules.

However, it was also discovered that in order for such an incorporation to be initiated and established successfully, essentially acting as change to the current approach to teaching and learning, there is a reliance on the instructional expertise of LD's in laboratories.

The opportunity which has been identified amongst the challenges that General Chemistry modules present relates to the development of the LD's teaching skills. It is believed that the development of these skills could begin to tackle and resolve some of the aforementioned subjective and objective challenges whilst providing further opportunities for both LD's and undergraduate students to experience a greater array of learning experiences. 


\section{References}

Austin, A. E., \& McDaniels, M. (2006). Preparing the professoriate of the future: Graduate student socialization for faculty roles HIGHER EDUCATION: (pp. 397-456): Springer.

Cacciatore, K. L., \& Sevian, H. (2009). Incrementally Approaching an Inquiry Lab Curriculum: Can Changing a Single Laboratory Experiment Improve Student Performance in General Chemistry? Journal of Chemical Education, 86(4), 498.

Chatterjee, S., Williamson, V. M., McCann, K., \& Peck, M. L. (2009). Surveying students' attitudes and perceptions toward guided-inquiry and open-inquiry laboratories. Journal of Chemical Education, 86(12), 1427.

Childs, P. E., \& Sheehan, M. (2009). What's difficult about chemistry? An Irish perspective. Chemistry Education Research and Practice, 10(3), 204-218.

Cooper, M. (2010). The case for reform of the undergraduate general chemistry curriculum. Journal of Chemical Education, 87(3), 231-232.

Crouch, C. H., \& Mazur, E. (2001). Peer instruction: Ten years of experience and results. American Journal of Physics, 69(9), 970-977.

Darmody, M., \& Fleming, B. (2009). 'The balancing act' -Irish part-time undergraduate students in higher education. Irish Educational Studies, 28(1), 67-83.

DeChenne, S. E., Enochs, L. G., \& Needham, M. (2012). Science, Technology, Engineering, and Mathematics Graduate Teaching Assistants Teaching Self-Efficacy. Journal of the Scholarship of Teaching and Learning, 12(4), 102-123.

Deters, K. M. (2005). Student opinions regarding inquiry-based labs. Journal of Chemical Education, 82(8), 1178.

Ege, S. N., Coppola, B. P., \& Lawton, R. G. (1997). The University of Michigan undergraduate chemistry curriculum 1 . Philosophy, curriculum, and the nature of change. Journal of Chemical Education, 74(1), 74.

Ezrailson, C. M. (2004). EMIT: Explicit modeling of interactive-engagement techniques for physics graduate teaching assistants and the impact on instruction and student performance in calculus-based physics. Texas A\&M University.

Feldon, D. F., Peugh, J., Timmerman, B. E., Maher, M. A., Hurst, M., Strickland, D., Stiegelmeyer, C. (2011). Graduate students' teaching experiences improve their methodological research skills. Science, 333(6045), 1037-1039.

Forfás, (2007). Tomorrow's Skills: Towards a National Skills Strategy. Dublin: Expert Group on Future Skills Need Group.

Francisco, J. S., Nicoll, G., \& Trautmann, M. (1998). Integrating multiple teaching methods into a general chemistry classroom. Journal of Chemical Education, 75(2), 210.

French, D., \& Russell, C. (2002). Do graduate teaching assistants benefit from teaching inquiry-based laboratories? BioScience, 52(11), 1036-1041.

Hammrich, P. L. (2001). Preparing graduate teaching assistants to assist biology faculty. Journal of Science Teacher Education, 12(1), 67-82.

Havighurst, R. J. (1929). Reform in the chemistry curriculum. Journal of Chemical Education, 6(6), 1126.

Henderson, C., Beach, A., \& Finkelstein, N. (2011). Facilitating change in undergraduate STEM instructional practices: an analytic review of the literature. Journal of Research in Science Teaching, 48(8), 952-984.

Higher Education Authority, (2014). Key Facts and Figures: Higher Education 2012/2013. Dublin: National Office for Equity of Access to Higher Education, Higher Education Authority.

Hofstein, A., \& Lunetta, V. N. (2004). The laboratory in science education: Foundations for the twenty-first century. Science Education, 88(1), 28-54. 
Lawrie, G., Wright, A., O'Brien, G., Bedford, S., Schultz, M., Dargaville, T., ... Thompson, C. (2013). Using formative feedback to identify and support first year chemistry students with missing or misconceptions. A practice report.

Lee, H. S., Linn, M. C., Varma, K., \& Liu, O. L. (2010). How do technology-enhanced inquiry science units impact classroom learning? Journal of Research in Science Teaching, 47(1), 71-90.

Lloyd, B. W., \& Spencer, J. N. (1994). The forum: New directions for general chemistry: Recommendations of the task force on the general chemistry curriculum. Journal of Chemical Education, 71(3), 206.

Luft, J. A., Kurdziel, J. P., Roehrig, G. H., \& Turner, J. (2004). Growing a garden without water: Graduate teaching assistants in introductory science laboratories at a doctoral/research university. Journal of Research in Science Teaching, 41(3), 211-233.

Martin, M. O., Mullis, I. V., Foy, P., \& Stanco, G. M. (2012). TIMSS 2011 International Results in Science: ERIC.

McDonough, K. (2006). Action research and the professional development of graduate teaching assistants. The Modern Language Journal, 9O(1), 33-47.

National Research Council. (1996). National Science Education Standards. Washington DC: National Academy Press.

Nurrenbern, S. C., Mickiewicz, J. A., \& Francisco, J. S. (1999). The impact of continuous instructional development on graduate and undergraduate students. Journal of Chemical Education, 76(1), 114.

OECD (2014). The PISA 2012 Results in Focus: What 15 year-olds know and what they can do with what they know. Paris: OECD Publications. Partridge, L., Hunt, L., \& Goody, A. (2013). Futureproofing university teaching: An Australian case study of postgraduate teacher preparation. Practice and Evidence of the Scholarship of Teaching and Learning in Higher Education, 8(2).

Partridge, L., Hunt, L., \& Goody, A. (2013). Future-proofing university teaching: An Australian case study of postgraduate teacher preparation. Practice and Evidence of the Scholarship of Teaching and Learning in Higher Education, 8(2).

Pavelich, M. J., \& Abraham, M. R. (1979). An inquiry format laboratory program for general chemistry. Journal of Chemical Education, 56(2), 100.

Regan, Á., Childs, P., \& Hayes, S. (2011). The use of an intervention programme to improve undergraduatestudents' chemical knowledge and address their misconceptions. Chemistry Education Research and Practice, 12(2), 219-227.

Sandi-Urena, S., Cooper, M. M., \& Gatlin, T. A. (2011). Graduate teaching assistants' epistemological and metacognitive development. Chemistry Education Research and Practice, 12(1), 92-100.

Seymour, E. (2002). Tracking the processes of change in US undergraduate education in science, mathematics, engineering, and technology. Science Education, 86(1), 79-105.

Shannon, D. M., Twale, D. J., \& Moore, M. S. (1998). TA teaching effectiveness: The impact of training and teaching experience. Journal of Higher Education, 440-466.

Sumter, T. F., \& Owens, P. M. (2011). An approach to teaching general chemistry II that highlights the interdisciplinary nature of science. Biochemistry and Molecular Biology Education, 39(2), 110-116.

Taft, H. L. (1997). National Curriculum Survey of College General Chemistry (1993). Journal of Chemical Education, 74(5), 595.

Tobias, S. (1992). Revitalizing Undergraduate Science: Why Some Things Work and Most Don't. An Occasional Paper on Neglected Problems in Science Education: ERIC.

Weaver, G. C., Russell, C. B., \& Wink, D. J. (2008). Inquiry-based and research-based laboratory pedagogies in undergraduate science. Nature chemical biology, 4(10), 577-580.

Xu, H., \& Talanquer, V. (2012). Effect of the Level of Inquiry of Lab Experiments on General Chemistry Students' Written Reflections. Journal of Chemical Education, 9o(1), 21-28. 